\title{
Tanggung Jawab Sejarah dan Kebudayaan di Balik Pelarangan Buku di Indonesia
}

\author{
Anak Agung Ayu Rai Wahyuni \\ Prodi Ilmu Sejarah, Fakultas Ilmu Budaya, Universitas Udayana \\ Ajungayu29@gmail.com \\ Denpasar, Provinsi Bali, Indonesia
}

\begin{abstract}
Book prohibition in Indonesia has been going on since the first President of the Republic of Indonesia, Soekarno. This prohibition continued in greater quality and quantity during the reign of the second President of the Republic of Indonesia, Soeharto. In the reform era, when freedom of expression found its space, book prohibition continued. This article examines the historical and cultural responsibility behind book banning. How about the prohibition of books in the Soekarno, Suharto era, and the reform era. What are the pros and cons that occur, as well as what solutions satisfy various parties. The method used is the library method, by reading, inputting data, and studying based on library data. This article explains that the author of the book must be responsible for the content of his writing. Themes such as the Movement of the PKI are sensitive themes, therefore writers must have historical and cultural awareness. Likewise, the government is expected to be able to review a book, and not to unilaterally freeze or ban it. Bringing a book into the realm of law is supported by the necessary evidence, so that all parties get justice based on the law, history and culture of the nation for the unity of the Republic of Indonesia based on the pillars of development and survival as a nation.
\end{abstract}

Keywords: Book prohibition, history, culture, pillars of development.

\begin{abstract}
Abstrak
Pelarangan buku di Indonesia sudah berlangsung sejak kekuasaan Presiden RI pertama, Soekarno. Pelarangan ini berlangsung terus dalam kualitas dan kuantitas yang lebih besar pada masa kekuasaan Presiden RI kedua, Soeharto. Pada era reformasi, ketika kebebasan epskresi menemukan ruangnya, pelarangan buku tetap terjadi. Artikel ini membahas tanggung jawab sejarah dan kebudayaan di balik pelarangan buku. Bagaimana pelarangan buku pada era Soekarno, Soeharto, dan era reformasi. Bagaimana pro-kontra yang terjadi, serta bagaimana solusi yang memuaskan berbagai pihak. Metode yang digunakan adalah metode pustaka, dengan membaca, menginput data, dan mengkaji berdasarkan data pustaka. Artikel ini menjelaskan bahwa penulis buku mesti bertanggung jawab terhadap kandungan tulisannya. Tema-tema seperti G-30-S PKI adalah tema yang sensitif karenanya penulis wajib memiliki kesadaran sejarah dan budaya. Demikian pula pihak pemerintan diharapkan dapat mengkaji sebuah buku, dan tidak melakukan pembekuan atau pelarangan secara sepihak. Membawa sebuah buku ke dalam ranah hukum didukung pembuktian yang diperlukan, agar semua pihak mendapatkan keadilan berdasarkan hukum, sejarah, dan kebudayaan bangsa demi persatuan NKRI berdasarkan pilar-pilar pembangunan dan keberlangsungan hidup sebagai sebuah bangsa.
\end{abstract}

Kata kunci: Pelarangan buku, sejarah, kebudayaan, pilar pembangunan.

\section{PENDAHULUAN}

Mengapa buku diarang beredar dalam sebuah negara yang mengedepankan demokrasi sebagai salah satu pilar pembangunan? Pertanyaan ini menarik untuk dijelaskan. "Jika kita mengatakan bahwa Indonesia adalah negara yang demokratis, maka harus ada jaminan terhadap freedom of 
expression, freedom of speech, dan freedom of the press. Dalam perspekti yang lebih umum, jenis jaminan tersebut dibutuhkan sebagai hak dasar sosial dan politik warga negara. Tanpa adanya jaminan tersebut, tak akan ada demokrasi" (Siregar, 2011:xiii).

Jaminan terhadap freedom of expression, freedom of speech, dan freedom of the press berkaitan dengan ekspresi, berbicara atau mewartakan, dan ekspresi. Kebebasan ekspresi dijamin undang-undang karenanya upaya untuk membatasinya dengan berbagai argumentasi mestinya berhadapan juga dengan undang-undang. Sama halnya dengan kebebasan berbicara, mewartakan, atau menyampaikan pendapat melalui penerbitan buku serta bentuk publikasi lainnya, dilindungi undang-undang. Apabila menimbulkan persoalan -misalnya publikasi buku dilarang- undang-undang pula yang menyelesaikannya Setiap warga negara memiliki hak untuk berbicara dibarengi dengan tanggung jawab terhadap apa yang disuarakannya.

Pelarangan buku di Indonesia sudah terjadi sejak masa kolonial, dilanjutkan pada masa kemerdekaan, orde lama, orde baru, dan juga masa reformasi. Pada umumnya pelarangan buku dilakukan secara sepihak oleh pihak penguasa, tanpa memberi kesempatan kepada penulis dan para ahli terkait untuk melakukan pembelaan terhadap kebebasan ekspresinya. Tanggung jawab penulis buku dalam hal ini dikekang langsung dalam bentuk pelarangan. Hal ini menyebabkan protes terhadap pelarangan buku tetap terjadi.

Meskipun 'protes' terhadap pelarangan buku tetap dilancarkan, kenyataannya catatan tentang pihak yang pro (pelarang) tetap melakukan pelarangan berdasarkan UU No. 4/PNPS/1963. Argumentasinya jelas, yaitu buku-buku yang dilarang beredar karena dianggap mengganggu ketertiban umum dan bertentangan dengan UUD 1945 dan Pancasila. Akan tetapi pada sisi lain pihak yang kontra terhadap pelarangan itu memiliki sikap yang menegaskan bahwa pelarangan adalah paradoks bagi kebebasan bermedia sebagaimana disebutkan berikut ini.

Pelarangan buku adalah paradoks bagi kebebasan bermedia yang telah dirasakan bangsa Indonesia selama lebih dari satu dekade terakhir. Pelarangan ini juga bentuk kesewenang-wenangan dalam membatasi kebebasan berpikir dan berpendapat di negara demokrasi. Pemberedelan buku ibarat sebuah "aborsi" yang membunuh generasi yang akan dilahirkan. Alih-alih mengantisipasi ancaman polemik dan ketertiban umum, pelarangan buku oleh negara mengindikasikan paranoia penguasa atas ancaman terhadap kekuasaan yang sedang berjalan (Yusuf, dkk. 2011:3).

Pandangan kritis di atas mengindikasikan bahwa pro-kontra mengenai pelarangan buku adalah hal yang serius tentang sejarah, regulasi, kebijakan yang berkaitan dengan publikasi dan buku. Di samping itu kritisi terhadap kesewenangwenangan, pembatasan kebebasan berpikir, ancaman kekuasaan, dan hal-hal lain dapat melahirkan kontradiksi-kontradiksi dalam masyarakat. Tulisan ini akan menjelaskan beberapa catatan di balik pelarangan buku di Indonesia, dengan dua rumusan masalah yang berkaitan dengan: 1) bagaimanakah latar belakang sejarah pelarangan buku; 2) bagaimanakah tanggung jawab kebudayaan tentang pelarangan buku. Metode yang digunakan adalah metode pustaka dengan mengandalkan studi pustaka sebagai sumber data utama.

\section{METODE}

Metode yang dilakukan adalah dengan mengumpulkan segala bentuk dokumen melalui studi pstaka, dengan mengumpulkan referensi yangberhubungan dengan pelarangan buku di Indonesia. Data diperoleh melalui review kepustakaan dan laporan penelitian.

Metodologi yang digunakan dijadikan sebagai alat pengamat sehingga tanggung jawab sejarah dan kebudayaan dibalik pelarangan buku di Indonesia dapat terungkap secara kritis dan objektif dan dapat mengungkap aspek secara kronologis (Sartono, 2016). Sehubungan dengan hal tersebut sangat dibutuhkan alat-alat analisis, konseptual, dan teoritis yang dicantumkan dan metodologi yang digunakan (Kuntowijoyo, 2003). Pendekatan yang digunakan adalah pendekatan structural, yang akan mengungkap konteks situasi yang terjadi, yang bersama yntuk mengungkapkan 
permasalahan mengenai kondisi apa saja yang mendukung latar belakang sejarah pelarangan buku dan tanggung jawab kebudayaan tentang pelarangan buku.

\section{KERANGKA TEORI}

\section{Teori Hegemoni}

Hegemoni menurut Gromsci, adalah hegemoni dengan kepemimpinan intelektual dan moral yang bernuansa positif. Gagasan Hegemoni Gramsci mengandung isu-isu pokok dalam studi kultural seperti pluralisme, multikultural, dan budaya marginal. Hegemoni adalah sebagai suatu dominasi kekuasaan suatu kelas sosial atas kelas sosial lainnya melalui pengaruh intelektual dan moral yang dibantu dominasi atau penindasan.

Intelektual dalam Hegemoni Gramsci dipahami sebagai suatu strata sosial yang menyeluruh yang menjalankan suatu fungsi organisasional dalam pengertian luas. Jadi intelektual bisa mencakup bidang kebudayaan atau administrasi politik.

\section{HASIL DAN PEMBAHASAN}

Pelarangan buku di Indonesia masih terjadi pada era reformasi. Ketika pandangan tentang kebebasan berpikir dan berekspresi mencapai puncaknya setelah era orde baru runtuh (ditandai dengan lengsernya Presiden RI ke-2 Soeharto dari tahta kekuasaan setelah 32 tahun menjadi presiden). Catatan ini menjelaskan bahwa sejarah tidak berakhir begitu saja, ada jejak-jejak yang tidak mudah dihapuskan, dan mengikuti alur perjalanan sebuah bangsa besar, Indonesia. Dalam sejarahnya Indonesia pernah mengalami paceklik buku (book starvation) (1970). UNESCO (1973) mencatat tidak ada satupun judul buku yang terbit dan dijual di pasaran. Hal ini merupakan akibat dari pencabutan subsidi kertas oleh pemerintah sejak tahun 1965. Penerbitan buku kembali terjadi setelah pemerintah Orde Baru membuat proyek buku inpres (https:news.detik.com/berita). Jumlah buku yang beredar meningkat dan penerbit pun bergerak kembali. Hal ini ternyata tidak "menghentikan" langkah-langkah pemerintah untuk melakukan pelarangan buku, terutama buku-buku yang isinya maupun penulisnya dipandang berseberangan dengan visi, misi, dan tujuan politik penguasa.

Untuk memahaminya dengan lebih mudah dan terstruktur, pelarangan buku dapat dicermati dengan memperhatikan sejarah, tokoh, dan peristiwa secara periodik yaitu: era demokrasi terpimpin, era orde baru, dan era reformasi.

\section{Pelarangan Buku Pada Era Demokrasi Terpimpin}

Pada $14 \quad$ - $17 \quad$ Maret 2010 diselenggarakan Pameran Pelarangan Buku di Taman Ismail Marzuki (TIM), Cikini, Jakarta Pusat. Pameran diselenggarakan atas kerja sama Lembaga Studi dan Advokasi Masyarakat (ELSAM), Institut Sejarah Sosial Indonesia (ISSI), dan Grafisosial Indonesia. Perjalanan panjang pelarangan buku di Indonesia diuraikan secara apik dalam tiga buah infografis. Untuk mendramatisir suasana, dibuatlah replika penjara dengan jeruji berwarna hitam. Di dalamnya, terdapat ratusan judul buku, berserta sejumlah covernya, yang dilarang sejak tahun 1959 (https:news.detik.com/berita). Pameran tersebut direfleksikan sejarah panjang pelarangan buku yang disahkan melalui berbagai regulasi sebagaimana tercatat berikut ini.

1. No 23/perpu/1959 memberi wewenang militer melarang buku dan menutup percetakan. Berdasarkan Perpu ini buku berjudul Hoakiau di Indonesia dilarang beredar. Pramoedya Ananta Toer penulisnya dipenjarakan selama satu tahun. Tiga buku kumpulan puisi juga dilarang beredar pada waktu itu. Salah satu buku kumpulan puisi karya Sabar Anantaguna yang berjudul Yang Bertanahair tapi Tak Bertanah, sementara dua lainnya karya Agam Wispi yang berjudul Yang Tak Terbungkamkan dan Matinya Seorang Petani (Lekra, 1961). Pamflet Demokrasi Kita karya Mohammad Hatta juga tidak lolos dari pembrangusan (https:news.detik.com/berita).

Sebelumnya (Sepanjang 1957), penguasa melarang penerbitan dari 33 penerbitan dan menutup tiga kantor berita - termasuk di antaranya Kantor Berita Antara. 
2. Penetapan Presiden No. 4 Tahun 1963 memberi kewenangan penuh pada Kejaksaan Agung untuk melarang peredaran barang-barang cetakan yang dianggap dapat mengganggu ketertiban umum. Berdasarkan perpres ini Presiden I RI Soekarno melarang pendukung Manifesto Kebudayaan (MK). Sastrawan yang tergabung dalam MK dipersempit ruang gerak publikasi karya-karyanya. Selanjutnya pada masa Presiden II RI, Soeharto (sekitar 1966) Lembaga Kebudayaan Rakyat (Lekra) dan 70-an judul buku karya para senimannya dilarang.

Buku-buku yang dilarang beredar pada waktu itu antara lain:

1. Hoakiau di Indonesia oleh Pramoedya Ananta Toer

2. Yang Bertanah Air tapi Tak Bertanah oleh Sabar Antaguna

3. Demokrasi Kita oleh Mohammad Hatta

4. Matinya Seorang Petani oleh Agam Wispi

5. Yang Tak Terbungkamkan (tanpa keterangan penulis) (Yusuf, dkk, 2011:191).

\section{Pelarangan Buku Pada Era Orde Baru}

Sejarah orde baru ditandai dengan peristiwa "Gerakan 30 September" yang dikenal dengan singkatan G30S. Sebuah gerakan yang menjadi salah satu "titik hitam" dari ujian terberat dalam sejarah perjalanan Negara Kesatuan Republik Indonesia (NKRI). Peristiwa ini berlanjut pada penumpasan lembaga-lembaga yang dicurigai berafiliasi pada PKI serta segala hal yang berkaitan dengannya. Stereotipe PKI selanjutnya menjadi momok yang menakutkan bagi siapapun yang "terkategori" "melawan" pemerintah. Pada masa inilah lahir:

1. Komando Pemulihan Keamanan dan ketertiban (Kopkamtib) - tepatnya dibentuk pada 10 Oktober 1965 yang bertugas memulihkan keamanan dan ketertiban.

2. Tap MPR XXV/ MPRS/ 1966 yang membubarkan PKI dan melarang ajaranajaran Marxisme-Leninisme/ Komunisme.

3. Oktober 1989 Kejaksaan Agung membentuk Clearing House yang berfungsi meneliti isi sebuah buku dan memberi rekomendasi langsung kepada Jaksa Agung. Melalui SK No. Kep-114/ JA/ 10/ 1989, clearing house secara resmi bekerja di bawah Jaksa Agung. Clearing house terdiri atas 19 anggota yaitu JAM Intel dan Subdirektorat bidang pengawasan media massa, Bakorstanas, Bakin, Bais, ABRI (kemudian menjadi BIA), Departemen Penerangan, Departemen Pendidikan dan Kebudayaan, serta Departemen Agama.

4. Instruksi Menteri Pendidikan Dasar dan Kebudayaan RI no. 1381/1965 tentang larangan mempergunakan buku-buku pelajaran yang penulisnya berasal dari ormas tertentu.

5. Selain Departemen P\&K, Menteri Perdagangan dan Koperasi juga mengeluarkan Keputusan Menteri no. 286/ KP/ XII/ 78 yang diturunkan dalam Keputusan Direktur Jenderal Perdagangan Luar Negeri No. 01/ DAGLU/ KP/ III/ 79 melarang impor, perdagangan, dan pengedaran segala jenis barang cetakan dalam huruf/ aksara dan bahasa Cina.

Buku-buku yang dilarang beredar pada masa Orde Baru mencatat sejarah kelam tentang argumentasi maupun jumlah buku yang dilarang beredar. Buku (novel) karya Pramoedia Ananta Toer yang terbanyak (12 buku) bahkan penulisnya pun terpenjara akibat buku-buku (novel) yang ditulisnya. Berdasarkan catatan Yusuf dkk (2011) jumlah buku yang dilarang beredar adalah sebagai berikut.

Pelarangan oleh Pembantu Menteri P.D. Dan K Bidang Teknis Pendidikan Kol (Inf.) Drs. M. Setiadi Kartohadikusumo pada 30 November 1965: 238 judul. Pelarangan oleh Kejaksaan Agung 1969 berjudul Funk and Wagnalls Standard Reference Encyclopedi. Selanjutnya hampir setiap tahun sejak 1969 sampai 1997 terjadi pelarangan antara lain Era Baru, Pemimpin Baru: Badio Menolak Rekayasa Rezim Orde Baru oleh Soebadio Sastrosatomo. Pelarangan terbanyak yang dilakukan Kejaksaan Agung terjadi pada tahun 1985 yaitu 29 judul antara lain: Akhlaq Oilitik Orde Baru di Mata Umat dan Sorotan AlQur'an oeh A.M. Fatwa, Indonesia di 
Persimpangan Jalan oleh M. Natsir, dan Dialog Tertulis Islam Kristen oleh Hamran Ambrie (Yusuf, dkk, 2011: 191-204).

\section{Pelarangan Buku Pada Era Reformasi}

Setelah 32 tahun ruang gerak demokrasi di"kekang" dengan berbagai kebijakaan dan kekuasaan orde baru, gerakan reformasi secara berani mengembalikan demokrasi pada posisinya. Kemerdekaan berkumpul dan berpendapat menemukan ruang yang ditandai dengan upaya menggarisbawahi kembali UUD Negara RI Tahun 1945. Pada 2004, DPR mencabut kewenangan Kejaksaan Agung untuk melarang peredaran barang cetakan melalui UU No. 16 Tahun 2004 tentang Kejaksaan RI.

Kenyataannya pelarangan buku terjadi lagi. Tahun 2006 Kejaksaan Agung kembali melarang peredaran buku berdasarkan UU No. 4/PNPS/1963, yang dilahirkan pada masa demokrasi terpimpin era Presiden I RI, Soekarno. Buku-buku yang dilarang serta penjelasannya dijelaskan berikut. 13 buku teks sejarah untuk SLTP dan SLA yang mengacu pada Kurikulum 2004.

Kejaksaan Agung berdalih buku-buku tersebut memutar balik sejarah karena tidak mencantumkan kata 'PKI' dibelakang 'G-30S' dan tidak memasukkan Peristiwa Madiun 1948. Kejaksaan Tinggi Pangkal Pinang bahkan memperluas pelarangan hingga mencakup 54 judul buku sejarah.

Tidak hanya pelarangan yang dilakukan kejaksaan, tetapi juga pemusnahan dengan cara membakar buku-buku teks yang disita. Pada akhir $2009 \quad$ Kejaksaan Agung melarang lima buku, diantaranya karya John Roosa, Dalih Pembunuhan Massal: Gerakan 30 September dan Kudeta Suharto (ISSI \& Hasta Mitra, 2008) serta karya Rhoma Dwi Yulianti dan Muhiddin M Dahlan, Lekra tak Membakar Buku: Suara Senyap Lembar Kebudayaan Harian Rakyat 1950-1965(Yogyakarata: Merakesumba, 2008).

Buku-buku itu dilarang karena dianggap 'dapat mengganggu ketertiban umum'. Kejaksaan Agung memonopoili definisi atas 'ketertiban umum' dan tidak merasa perlu membuktikan bahwa peredaran buku itu memang meresahkan masyarakat. Padahal buku-buku itu telah beredar selama satu tahun atau lebih tanpa menimbulkan gejolak sama sekali.

(https://sites.google.com/site/sejarahsosial/pe laranganbuku). Pelarangan buku pada era reformasi adalah sebuah tamparan keras terhadap demokrasi. Buku yang berhubungan dengan kebebasan ekspresi, dan tanggung jawab dan kecerdesan penulis dan pembaca, kembali dilarang. Hal ini jelas bertentangan dengan karakter bangsa dan masyarakat Indonesia yang pluralistik dan multikultural sebagaimana dijelaskan dalam kutipan berikut ini.

Indonesia sekarang adalah negara demokrasi terbesar ketiga di dunia, yang menjadi mercusuar bagi toleransi dan pluralisme di Asia. Penelitian atas pelarangan buku ini ditujukan untuk memberikan kontribusi konstruktif bagi pemeliharaan demokrasi di Indonesia, yang oleh dunia dapat dijadikan sebagai penanda (trademark) masyarakat Indonesia yang pluralistik (Schweisshelm, 2011:xx).

Pandangan di atas menegaskan bahwa pemeliharaan demokrasi adalah tanggung jawab setiap warga negara Indonesia. Tanggung jawab tersebut adalah upaya untuk menegakkan hakekat kemanusiaan dalam negara demokrasi. Sebagaimana dijelaskan Schweisshelm, (2011:xxi), bahwa isu pelarangan buku sangat menyentuh pengalaman sejarah di Jerman sampai era NAZI berkuasa; sebagaimana juga pengalaman sejarah Indonesia sejak masih sebagai negara jajahan (Belanda dan Jepang), sampai saat ini.

Tanggung Jawab Sejarah dan Kebudayaan Terhadap Pelarangan Buku di Indonesia Tahun 2011 Pemantau Regulasi dan Regulator Media (PR2Media) dan Yayasan Friedrich Elbert atau Friedrich Elbert Stiftung (FES) melakukan penelitian dan penerbitan laporan penelitian tentang pelarangan buku. Hasilnya diterbitkan oleh PR2Media berjudul Pelarangan Buku di Indonesia: Sebuah paradoks Demokrasi dan Kebebasan Berekspresi (Edisi revisi) (2011). Hasil penelitian tersebut merupakan refleksi masyarakat pembaca buku tentang sejarah dan budaya pelarangan buku di Indonesia sebagai bagian dari sejarah pelarangan buku bahkan Penghancuran Buku dari Masa ke Masa (Baez, 2013) pada tingkat dunia. 
Regulasi yang cenderung dipakai oleh Kejaksaan Agung untuk membenarkan pelarangan buku di Indonesia adalah Undang-Undang no.4/PNPS/1963 tentang pengamanan barang-barang cetakan yang isinya dapat mengganggu ketertiban umum. Uji materi UU No. 4/PNPS/1963 ini dilakukan Mahkamah Konstitusi (MK) dalam masa kepemimpinan Mahfud MD sebagaimana dijelaskan sebagai berikut.

Ketua Mahkamah Konstitusi, Mahfud MD mengatakan undang-undang No.4 PNPS tahun 1963 yang digunakan Kejaksaan Agung untuk melakukan pelarangan dan penyitaan buku sangat bertentangan dengan konstitusi Indonesia. Menurut Mahfud, ini karena setiap orang berhak untuk berkomunikasi, menyimpan dan menyatakan fikirannya melalui pembuatan buku. Kejaksaan Agung harus melalui proses peradilan terlebih dahulu apabila ingin melakukan pelarangan buku yang dinilainya mengganggu ketertiban umum. Jika ingin melakukan penyitaan buku maka kepolisian maupun Kejaksaan Agung harus meminta ijin kepada ketua Pengadilan Negeri setempat yang kemudian dilanjutkan dengan proses penyidikan, penuntutan dan penyidangan yang sesuai dengan undangundang yang ada (https://www.voaindonesia.com/a/104876414 /84830).

Sementara itu ditegaskan juga oleh Siregar bahwa bila kita memang memilih demokrasi sebagai jalan hidup berbangsa dan bernegara sebagaimana dinyatakan oleh UUD 1946 dan UU Pers No. 4/1999. maka UU No. 4/PNPS/1963 harus dinyatakan tidak berlaku dan pelarangan buku harus dicabut (Siregar, 2011:xvii). Pelarangan buku dipandang sebagai ekspresi dari banyak argumentasi yang pro maupun yang kontra. Pihak yang kontra mengatakan bahwa pelarangan buku menunjukkan upaya memandulkan cara berpikir, ketakutan penguasa, pemaknaan tunggal, serta pembodohan massal karena daya kritis masyarakat dibatasi (Yusuf, 2011:v-vi). Sebagaimana dijelaskan Yusuf, pada masa reformasi buku-buku yang pernah dilarang beredar antara lain sebagai berikut: 1) Dalih Pembunuhan Massal: Gerakan 30 September dan Kudeta Suharto karya John
Rosa; 2) Suara Gereja Bagi Umat Tertindas: Penderitaan Tetesan Darah dan Cucuran Air Mata Umat Tuhan di Papua Barat Harus Diakhiri karya Socratez Sofian Yoman; 3) Lekra Tak Membakar Buku: Suara Senyap Lembar Kebudayaan Pikiran Rakyat 1950 1965 karya Rhoma Dwi Aria Yuliantri dan Muhidin M. Dahlan; 4) Enam Jalan Menuju Tuhan karya Darmawan; 5) Mengungkap Misteri Keberagaman Beragama karya Sahrudin Ahmad (Yusuf, dkk: 2011: 1).

Mengapa buku-buku dilarang? Mengapa prokontra tentang buku tetap terjadi? Hamdan Zoelva salah satu hakim konstitusi pada masa kepemimpinan Mahfud MD adalah satusatunya hakim dari sembilan hakim yang mendukung pelarangan buku oleh Kejaksaan Agung.

"Apalagi dalam konteks masyarakat Indonesia yang sangat plural, ancaman atas keamanan dan ketertiban umum yang ditimbulkan oleh suku, ras dan agama masih menjadi persoalan yang belum dapat diatasi dengan baik," kata Hamdan Zoelva. (https://www.voaindonesia.com/104876414/ 84830).

Pro-kontra pelarangan buku memang perlu diatasi dengan putusan pengadilan. Kepala Pusat Penerangan Kejaksaan Agung Amir Yanto menegaskan bahwa sesuai dengan peraturan perundangan, kejaksaan hanya memiliki wewenang untuk meneliti apakah sebuah buku dikategorikan sebagai buku terlarang atau tidak. "Melalui salah satu putusan MK, pelarangan (buku) itu harus melalui putusan pengadilan. Kejaksaaan hanya meneliti isinya. (http://nasional.kompas.com/read/2016/05/18 ). Keputusan ini menjelaskan bahwa pelarangan buku dilakukan melalui prosedur dan keputusan hukum yang didukung undang-undang.

Pertanyaan tentang mengapa buku dilarang beredar hendaknya dicermati dalam kaitannya dengan sejarah, pendidikan, dan kebudayaan. Dari sidut sejarah misalnya, tokoh peristiwa dan waktu menjadi salah satu kunci jawaban yang patt dikaji ulang. Sejarah mencatat pula bahwa satu tema yang menjadi persoalan serta pro kontra sepanjang sejarah (sejak 1965) sampai saat ini adalah tema seputar G30S PKI. Tema ini sangat sensitif, karenanya pelarangan buku yang berkaitan 
dengannya masih terjadi dan menimbulkan pro-kontra. Kajian tentangnya wajib dilakukan untuk menjembatani pro-kontra tersebut. Memori dan sejarah G30S PKI masih berakar kuat, demikian pula fenomena yang "berusaha menghadirkan kembali isuisu G30S PKI ke dalam wacana politik. Ada kecenderungan sesama WNI saling menghakimi, mengkafirkan, menuduh, dan menjerumuskan memalui benturan kepentingan politik serta isu sara yang memecah belah. Bhineka Tunggal Ika, pancasila, NKRI di"racuni" dengan pemaksaan ideologi yang primordial dan memecah belah. Fenomena ini perlu diuraikan dan dikritisi berdasarkan karakter budaya yang bersatu pilar-pilarnya: pancasila, bhineka tunggal ika, UUD 45, NKRI. Dengan demikian buku-buku yang dicurigai memperlemah kekuatan NKRI "perlu dilarang" melalui proses hukum yang berlaku di Indonesia. Kejaksaan atau pihak mana pun tidak dapat bertindak secara sepihak untuk melarang buku-buku tertentu, akan tetapi melalui mekanisme hukum.

Menyikapi pelarangan buku, Masyarakat Literasi Yogyakarta (MLY) Adhe Ma'ruf dari Masyarakat Literasi Yogyakarta (Yogyakarta, Selasa (17/06/2016). Tujuh maklumat Masyarakat Literasi Yogyakarta dibacakan di Kantor Lembaga Bantuan Hukum (LBH) Yogyakarta oleh Muhidin M Dahlan, pegiat literasi di Indonesia. Isi maklumat itu yakni:

1) kebebasan berserikat, berkumpul, dan mengeluarkan pendapat di hadapan orang banyak lewat berbagai media adalah amanat reformasi dan konstitusi yang mesti dijaga serta dirawat bersama dalam kerangka kebhinnekaan sebagai bangsa; 2) setiap perselisihan pendapat atas pikiran yang berbeda hendaknya diselesaikan dengan jalan dialog dan/atau mimbar-mimbar perdebatan untuk memperkaya khasanah pengetahuan dan keilmuan; 3) segala bentuk pelarangan atas penerbitan buku dan produk-produk akal budi seyogyanya dilakukan pihak-pihak yang berwewenang atas seizin pengadilan sebagaimana diatur oleh hukum perundangan yang berlaku; 4) mendesak kepada lembaga Arsip Nasional Republik Indonesia (ANRI) untuk membuka secara bebas arsip-arsip negara yang terkait dengan tragedi 1965 dan pelanggaran HAM berat lainnya sebagai bagian dari upaya kita belajar dan memperkaya khasanah pengetahuan kesejarahan; 5) mendorong pemerintah, baik pusat dan daerah, menciptakan iklim perbukuan yang sehat, kompetitif, dan memberi perlindungan pada kerja penerbitan, diskusi buku, dan gerakan literasi yang inovatif sebagaimana diamanatkan preambule UUD 1945, yakni mencerdaskan kehidupan bangsa; 6) asas, kerja umum, dan kegiatan harian ekosistem perbukuan membutuhkan aturan main yang jelas dan mengikat semua ekosistem yang bernaung di dalamnya. Oleh karena itu, mendesak Pemerintah dan DPR RI untuk menggodok dan segera mengesahkan UU Sistem Perbukuan Nasional yang demokratis; 7) mendesak Ikatan Penerbit Indonesia (IKAPI) sebagai salah satu dari asosiasi penerbit buku yang menjadi mitra pemerintah dan sudah berpengalaman dalam sejarah panjang perbukuan nasional senantiasa mengambil peran yang signifikan dan aktif-responsif untuk membangun komunikasi yang sehat dengan elemen-elemen masyarakat yang plural

(http://regional.kompas.com/read/2016/05/18 /06410121).

Dukungan terhadap KLY ditunjukkan pula oleh Sineas dan pengiat seni Garin Nugroho, Guntur Narwaya (Advokad), Faruk HT (Akedemisi dan Budayawan), Hamzal Wahyudin (Direktur LBH Yogya) dan Muhidin M Dahlan (penulis dan penggiat literasi)yang hadir pada momen penyampaian sikap KLY. Sikap Kelompok Literasi Yogyakarta (KLY) tersebut menggarisbawahi lagi pentingnya proses hukum -sebagai sebuah sikap budaya- untuk menentukan sebuah buku dilarang beredar.

\section{SIMPULAN}

Pelarangan buku di NKRI sudah terjadi sejak masa demokrasi terpimpin atau era orde lama di bawah kekuasaan Presiden Soekarno. Pada masa ini sedikitnya ada 5 (lima) buku yang dilarang beredar. Pada era kekuasaan Presiden Soeharto. Pelarangan buku terjadi dalam jumlah besar dengan peran utama Kementerian Pendidikan dan 
Kebudayaan juga Kejaksaan Agung. Sejak 1969 sampai 1997, hampir setiap tahun Kejaksaan Agung mengeluarkan keputusan tanpa melalui proses pengadilan- melarang buku tertentu. Pada era reformasi pelarangan buku masih terjadi. Bahkan sampai tahun 2009/2010 beberapa buku yang berkaitan dengan tema tertentu dilarang beredar.

Pro - kontra tentang pelarangan buku sampai pada uji material di Mahkamah Konstitusi. Regulasi yang cenderung dipakai oleh Kejaksaan Agung untuk membenarkan pelarangan buku di Indonesia adalah Undang-Undang no.4/PNPS/1963 tentang pengamanan barang-barang cetakan yang isinya dapat mengganggu ketertiban umum. Uji materi UU No. 4/PNPS/1963 dilakukan Mahkamah Konstitusi (MK) dalam masa kepemimpinan Mahfud MD. Keputusannya adalah Kejaksaan Agung harus melalui proses peradilan terlebih dahulu apabila ingin melakukan pelarangan buku yang dinilainya mengganggu ketertiban umum.

Tahun 2011 Pemantau Regulasi dan Regulator Media (PR2Media) dan Yayasan Friedrich Elbert atau Friedrich Elbert Stiftung (FES) melakukan penelitian dan penerbitan laporan penelitian tentang pelarangan buku. Hasilnya diterbitkan oleh PR2Media berjudul Pelarangan Buku di Indonesia: Sebuah paradoks Demokrasi dan Kebebasan Berekspresi (Edisi revisi) (2011). Hasil penelitian tersebut merupakan refleksi masyarakat pembaca buku tentang sejarah dan budaya pelarangan buku di Indonesia sebagai bagian dari sejarah pelarangan buku bahkan Penghancuran Buku dari Masa ke Masa (Baez, 2013) pada tingkat dunia.

Pernyataan sikap Masyarakat Literasi Yogyakarta (MLY) tentang pelarangan buku, juga menunjukkan bahwa jika ingin melakukan pelarangan buku -dalam bentuk dan isi apapun- maka kepolisian maupun Kejaksaan Agung harus meminta ijin kepada ketua Pengadilan Negeri setempat yang kemudian dilanjutkan dengan proses penyidikan, penuntutan dan penyidangan yang sesuai dengan undang-undang yang berlaku. Bila kita memang memilih demokrasi sebagai jalan hidup berbangsa dan bernegara sebagaimana dinyatakan oleh UUD 1946 dan UU Pers No. 4/1999, maka UU No. 4/PNPS/1963 harus dinyatakan tidak berlaku dan pelarangan buku harus dicabut (Siregar, 2011:xvii).

Pelarangan buku dipandang sebagai ekspresi dari banyak argumentasi yang pro maupun yang kontra. Pelarangan buku menunjukkan upaya memandulkan cara berpikir, ketakutan penguasa, pemaknaan tunggal, serta pembodohan massal karena daya kritis masyarakat dibatasi (Yusuf, 2011:v-vi). Pernyataan ini sangat keras mengkitisi pelarangan buku yang dilakukan pemerintah. Karenanya, pelarangan buku sepantasnya didasari tanggung jawab sejarah dan kebudayaan Indonesia sebagai jembatan.

Pihak pemerintah sebaiknya melakukan upaya-upaya hukum yang demokratis dan transparan untuk menentukan pelarangan. Pihak penulis, penerbit, dan masyarakat pembaca perlu terbuka untuk bertanggung jawab terhadap buku yang ditulis dan dibaca. Dengan demikian pelarangan buku adalah satu keputusan yang memiliki kedudukan hukum yang jelas dan dapat dipertanggungjawabkan.

\section{REFERENSI}

Dariyanto, Erwin, Beleid Pembredelan Warisan Kolonial, Koran Tempo, Edisi No. 3055 Tahun IX, 3 Januari 2010.

Dariyanto, Erwin, Lima Yang Dilarang, Koran Tempo, Edisi No. 3055 Tahun IX, 3 Januari 2010.

Dariyanto, Erwin dan Ika Ningtyas, Mengapa Masih Memberangus Buku, Koran Tempo, Edisi No. 3055 Tahun IX, 3 Januari 2010.

Manggiasih, Bunga, dkk, Penerbit Buku Ancam Somasi Kejaksaan, Koran Tempo, Edisi No. 3048 Tahun IX, 26 Desember 2009.

Kartodirjo, Sartono. 2016. Pendekatan Ilmu Sosial dalam Metodologi Sejarah. Yogyakarta : Ombak.

Kuntowijoyo. 2003. Metodologi Sejarah Edisi Kedua. Yogyakarta : Tiara Wacana. 
Sari, Dianing dan Anton Septian, Pelarangan Buku oleh Kejaksaan Dikecam, Koran Tempo, Edisi No. 3047 Tahun IX, 24 Desember 2009.

Septian, Anton, Dwi Riyanto Agustiar, dkk, Kejaksaan Akan Sita Buku yang

Dilarang, Koran Tempo, Edisi No. 3051 Tahun IX, 29 Desember 2009.

Stinati, Domonic. 2010. Popular Culture Pengantar Menuju Teori Budaya Populer. Yogyakarta : Ar-Ruzz Medua.

Awaluddin, Yusuf. dkk. 2011. Pelarangan Buku di Indonesia Sebuah Paradoks Demokrasi dan Kebebasan Berekspresi. Yogyakarta: PR2Media dan FES.

Barker, Chris. 2009. Cultural Studies: Teori dan Praktek (terj. Noerhadi dan Sihabul Millah) Yogyakarta: Kreasi Wacana.

Schweisshelm, Erwin. 2011. "Menolak Pelarangan Buku: Menjaga Pluralisme dan Demokrasi" dalam Pelarangan Buku di Indonesia Sebuah Paradoks Demokrasi dan Kebebasan Berekspresi. Yogyakarta: PR2Media dan FES.

https://sites.google.com/site/sejarahsosial/pel aranganbuku

https://www.voaindonesia.com/a/104876414/ 84830

https://www.voaindonesia.com/104876414/8 $\underline{4830}$

http://nasional.kompas.com/read/2016/05/18) 